\title{
Economic Effectiveness of Specialized Households of Project of Cattle Feeding Based on Crop Residues
}

\author{
Wenchao Cai ${ }^{1,2}$, Xueying Guo ${ }^{1,2, *}$, Yufeng Sun ${ }^{1,2}$ \\ ${ }^{1}$ College of Mechanical \& Electrical Engineering, Henan Agricultural University, Zhengzhou 450002, \\ China \\ ${ }^{2}$ Collaborative Innovation Center of Biomass Energy, Zhengzhou 450002, China \\ ${ }^{*}$ Corresponding author e-mail: 2279013276@qq.com
}

\begin{abstract}
Keywords: Cattle feeding based on crop residues (CFCR), Economic effectiveness; Opportunity costs;
\end{abstract} Model.

\begin{abstract}
The small-scale specialized households are the main body of the project of cattle feeding based on crop residues (CFCR), they are accounting for more than $90 \%$. However, the numbers is quickly declined in recent years for the poor economic effectiveness of specialized households. This paper explains why with the following research. The calculation method of the economic effectiveness of specialized households of CFCR is given based on the analysis of all the inputs and outputs, with the special indicator of profit-oriented of one cattle monthly, and the profits of the specialized households are measured by the opportunity costs of going out to work. A micro-level study is carried out in a typical county of center China to assess the above theory research.
\end{abstract}

\section{Introduction}

The project of cattle feeding based on crop residues (CFCR) has been implemented in China for 17 years. It is good to increase beef outputs, save in feed grain, and promote a virtuous circle of farming system with sustainable development [1]. The small-scale specialized households are the main body of CFCR according to the 2008 Chinese statistics yearbook of animal husbandry, the scale within 100 heads of the total numbers of beef cattle is accounting for $97.34 \%$, and the scale within 100 heads of all the feeding dairy cows is accounting for $98.7 \%$ [2]. But the numbers is quickly declined in recent years for the poor economic effectiveness of specialized households [3].

According to the model of CFCR with the core of the specialized households, which suited with the national conditions, it is necessary to study the economic effectiveness of specialized households of CFCR. So the government could take the management method of "seizing the middle, and promoting the others", and seize the scattered specialized households of CFCR with the support policies, and drive the other concentrated steps in this way, such like calf production, beef cattle fattening and dairy production, in order to promote the sustainable development of the industry of CFCR [3]. The paper is helpful to give the reasonable management methods for the government.

In this paper, we began by analyzing all the inputs and outputs of specialized households of CFCR; next, the calculation methods of the economic effectiveness are set up; thirdly, the profits of the specialized households are measured by the opportunity costs of going out to work; and finally, a micro-level study is carried out in a typical county of center China.

\section{The inputs and outputs}

The project of CFCR is a complete production activity, and has the general nature of economic activity, which is that it has inputs and outputs. The elements of the inputs and outputs of specialized households of CFCR are showed in figure 1. 


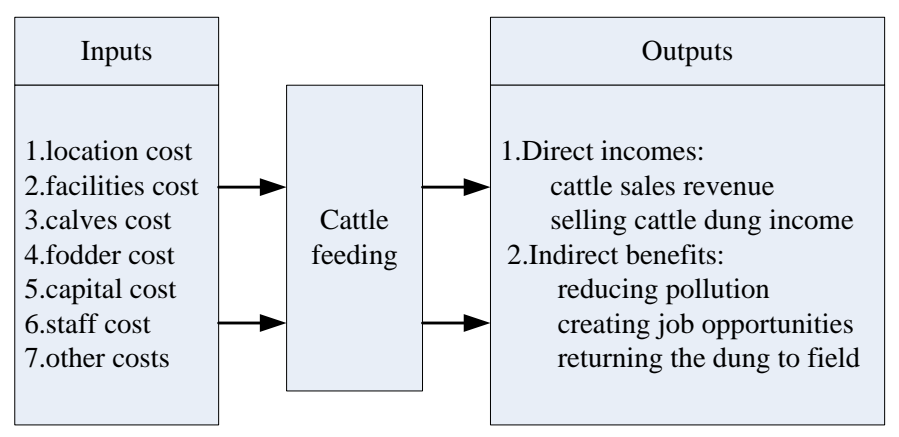

Fig1 Analysis of the relationship between input and output of CFCR by specialized households

The farmers of specialized households of CFCR would not give their labor payments by themselves. Therefore, the simple balance of the farmers is that the economic benefits of cattle feeding are equal to going out for a work. Otherwise, the farmers would prefer to work outside rather than feeding cattle in the home.

Here, we supposed the following situations of the typical specialized households of CFCR: The family has $L$ Labors of people; the common income of a labor yearly is $X \mathrm{RMB}$; the net profit of feeding one cattle is $A \mathrm{RMB}$; the minimum scale for cattle feeding is $Y$ heads; the labor conversion factor is $\mu(\mu=0.7)$. So we can get the following equation if not considering the time value of the capital:

$$
A \cdot Y \geq \mu \cdot L \cdot X
$$

Then, the formula of calculating the minimum scale for cattle feeding is got by rearranging the above equation.

$$
Y \geq \frac{\mu \cdot L \cdot X}{A}
$$

Here, we emphasize that all the parameters used in the equations are converted as the single cattle consume cost, and the cycle of feeding one cattle is $N$ months, the parameters of calculating economic benefits are shown in table 1 .

\begin{tabular}{|c|c|c|c|}
\hline & activities & symbol & unit \\
\hline \multirow{11}{*}{ inputs } & \multirow{2}{*}{$\begin{array}{l}\text { Land rental cost } \\
\text { Calf cost }\end{array}$} & $I_{1}$ & $\mathrm{RMB}$ \\
\hline & & $I_{2}$ & $\mathrm{RMB}$ \\
\hline & Crush fodder & $I_{3}$ & RMB \\
\hline & Concentrated fodder & $I_{4}$ & RMB \\
\hline & Labor cost & $I_{5}$ & RMB \\
\hline & Vaccine cost & $I_{6}$ & $\mathrm{RMB}$ \\
\hline & Water and fuel cost & $I_{7}$ & $\mathrm{RMB}$ \\
\hline & Transportation cost & $I_{8}$ & $\mathrm{RMB}$ \\
\hline & Depreciation cost of fixed assets & $I_{9}$ & RMB \\
\hline & Interest cost on the loan & $I_{10}$ & RMB \\
\hline & The total costs & $I$ & RMB \\
\hline \multirow{3}{*}{ outputs } & Selling cattle revenue & $O_{1}$ & RMB \\
\hline & Selling cattle dung income & $\mathrm{O}_{2}$ & $\mathrm{RMB}$ \\
\hline & The total incomes & $O$ & $\mathrm{RMB}$ \\
\hline \multirow{3}{*}{$\begin{array}{l}\text { economic } \\
\text { Effectiveness }\end{array}$} & Cost-profit margins & $\lambda$ & $\%$ \\
\hline & \multirow{2}{*}{ The profit of one cattle monthly } & $H$ & RMB \\
\hline & & $Z$ & RMB \\
\hline
\end{tabular}

Tab. 1 The economic benefits calculation parameters of CFCR of specialized households

The total costs include all the costs in the period of feeding one cattle, the formula is: 


$$
I=I_{1}+I_{2}+I_{3}+I_{4}+I_{5}+I_{6}+I_{7}+I_{8}+I_{9}+I_{10}
$$

The gross incomes include selling cattle revenue and selling cattle dung income, the calculation equation is the following:

$$
O=O_{1}+O_{2}
$$

\section{The model}

Here, we think that it is reasonable that the personal labor costs should not be included in the equations of calculating economic effectiveness of specialized households in order to compared profit with going out for a work.

The equation of calculating cost-profit margins is:

$$
\lambda=\frac{O-I}{O}
$$

The profit of one cattle monthly can be got with the following formula:

$$
H=\frac{O-I}{N}
$$

Thus, the net income of specialized households by one cattle would be as $A$, that can be calculated by the following formula:

$$
A=12 H=\frac{12(O-I)}{N}
$$

If $Y_{1}$ is heads of cattle by the specialized households yearly, then we got the net income of specialized households yearly, which as $E$,

$$
E=A Y_{1}
$$

The opportunity profit of going out for a work can be $D$, according to equation 1 and equation 2 , the formula is:

$$
D=\mu \cdot L \cdot X=A Y
$$

We supposed that $Z$ is the difference profits between cattle feeding and going out for a work, which can be got in the following formula:

$$
Z=E-D=A\left(Y_{1}-Y\right)
$$

It is easy to get the following condition:

$$
\text { If } Y_{1}<Y \text {, then } Z<0 \text {. }
$$

It tells us that the economic effectiveness is bad when the scale of specialized households of CFCR is too small, the situation of going out for a work would be in action.

\section{A micro-level study}

Early 2009, we conducted the survey of the project of CFCR in Yanshi County with the help of Animal husbandry bureau of Henan Province and Center for Control and Prevention of Animal Infectious Disease of the local government. The questionnaires about feeding beef cattle by specialized households are finished by the local people, which are chosen with stratified random sampling. The data sample is 60 , about $4.3 \%$ of the whole specialized households with different scale and different breeding methods.

\subsection{The regression model}

We use SPSS17.0 software to process the data. The statistical descriptions are shown in table 2 . 
As shown in Tab.2, the profit of one cattle monthly of specialized households in Yanshi County is $159 \mathrm{RMB}$ on average, and the maximum is $284 \mathrm{RMB}$, the minimum is $20 \mathrm{RMB}$.

Table 2. Descriptive statistics

\begin{tabular}{|c|c|c|c|c|c|c|}
\hline activities & unit & $\mathrm{N}$ & Min & Max & Mean & $\begin{array}{c}\text { Std. } \\
\text { Deviation }\end{array}$ \\
\hline Land rental cost (X1) & RMB & 60 & .00 & 7.50 & .5913 & 1.51144 \\
\hline Calf cost (X2) & $100 \mathrm{RMB}$ & 60 & .33 & 10.00 & 1.9548 & 2.04575 \\
\hline Crush fodder (X3) & $100 \mathrm{RMB}$ & 60 & .00 & 1.08 & .0411 & .16802 \\
\hline Concentrated fodder (X4) & $100 \mathrm{RMB}$ & 60 & .00 & 3.60 & .9968 & .59670 \\
\hline Labor cost (X5) & $10 \mathrm{RMB}$ & 60 & .00 & 2.67 & .1078 & .43901 \\
\hline Vaccine cost (X6) & $10 \mathrm{RMB}$ & 60 & .00 & 2.22 & .1215 & .36804 \\
\hline Water and fuel cost (X7) & RMB & 60 & .00 & 7.20 & 2.2835 & 1.60574 \\
\hline Transportation cost (X8) & RMB & 60 & .00 & 5.83 & .5247 & 1.28490 \\
\hline $\begin{array}{c}\text { Depreciation cost of } \\
\text { fixed assets(X9) }\end{array}$ & $10 \mathrm{RMB}$ & 60 & .08 & 4.89 & 1.2493 & 1.18093 \\
\hline $\begin{array}{c}\text { Interest cost on the } \\
\text { loan (X10) }\end{array}$ & $10 \mathrm{RMB}$ & 60 & .00 & 3.13 & .1253 & .53688 \\
\hline $\begin{array}{c}\text { Selling } \\
\text { cattle revenue(X11) }\end{array}$ & $100 \mathrm{RMB}$ & 60 & 1.21 & 15.75 & 4.7741 & 2.63141 \\
\hline $\begin{array}{c}\text { Selling cattle dung } \\
\text { income (X12) }\end{array}$ & RMB & 60 & .00 & 5.00 & .3274 & .94807 \\
\hline $\begin{array}{c}\text { The profit of one cattle } \\
\text { monthly (H) }\end{array}$ & $100 \mathrm{RMB}$ & 60 & .20 & 2.84 & 1.5902 & .65696 \\
\hline
\end{tabular}

Through analyzing the scatter and the correlations of descriptive statistics, we find the following costs that have strongly linear dependence relation with the profit of one cattle monthly $(\mathrm{H})$ : calf cost (X2), concentrated fodder (X4), water and fuel cost (X7), depreciation cost of fixed assets(X9), and selling cattle revenue(X11), so we let them to enter the predictive equation by presenting the enforced regression methods.

Then, the regression model of $H$ can be also got from the software in the following:

$$
\begin{aligned}
& \hat{H}=0.299-0.871 X_{2}-0.948 X_{4} \\
& -0.038 X_{7}-0.03 X_{9}+0.866 X_{11}
\end{aligned}
$$

\begin{tabular}{|c|c|c|c|c|c|c|c|c|c|}
\hline \multirow[b]{2}{*}{ Model } & \multirow[b]{2}{*}{$\mathrm{R}$} & \multirow[b]{2}{*}{$\begin{array}{c}\mathrm{R} \\
\text { Square }\end{array}$} & \multirow{2}{*}{$\begin{array}{l}\text { Adjusted R } \\
\text { Square }\end{array}$} & \multirow{2}{*}{$\begin{array}{l}\text { Std. Error } \\
\text { of the } \\
\text { Estimate }\end{array}$} & \multicolumn{5}{|c|}{ Change Statistics } \\
\hline & & & & & $\begin{array}{c}\text { R Square } \\
\text { Change }\end{array}$ & F Change & df1 & $\mathrm{df} 2$ & $\begin{array}{l}\text { Sig. F } \\
\text { Change }\end{array}$ \\
\hline 1 & $.961^{\mathrm{a}}$ & .923 & .916 & .19000 & .923 & 130.278 & 5 & 54 & .000 \\
\hline
\end{tabular}

Table 3.Model Summaryb

a. Predictors: (Constant), X11, X9, X7, X4, X2

b. Dependent Variable: $H$

Table 3 is the model summary made by the software. It tells us that the following information:

$R=0.961$, the correlation coefficient is 0.961 , and is very close to 1 , that indicates a strong linear relationship between the independent variables and the dependent variable;

$R^{2}=0.923$, the coefficient of determination is 0.923 , and

$R^{2}=0.916$, the adjusted determination coefficient is 0.916 , those means the regression model fits the data in a high level. The percentage is more than $91.6 \%$; the model has the strongly explanatory power. 
Table 4. Descriptive statistics of ANOVAb

\begin{tabular}{|c|c|c|c|c|c|c|}
\hline \multicolumn{2}{|c|}{ Model } & Sum of Squares & df & Mean Square & F & Sig. \\
\hline \multirow{3}{*}{1} & Regression & 23.515 & 5 & 4.703 & 130.278 & $.000^{\mathrm{a}}$ \\
\cline { 2 - 7 } & Residual & 1.949 & 54 & .036 & & \\
\cline { 2 - 6 } & Total & 25.464 & 59 & \\
\hline \multicolumn{7}{|c|}{ a. Predictors: (Constant), X11, X9, X7, X4, X2 } \\
\hline \multicolumn{7}{|c|}{ b. Dependent Variable: H }
\end{tabular}

Table4 is the descriptive statistics of ANOVA made by the software. We can get the following information:

$F=130.278$, the F-statistic is 130.278 , and at the same time, $p=0.000$, the signal statistic is much smaller than 0.0001 . All those indicate that the linear relationship between the independent variables and the dependent variable is clear, and the regression equation is statistically significant.

The residual analysis of the regression equation is as shown in figure 2, figure 3 and figure 4 .

We can think that the residual distribution is approximate to the normal distribution, and basically meet the assumption of homogeneity variance from these figures.

So we can essentially accept the model based the above tables and figures, and we also can get the useful information from the regression equation. The main factors that affecting the profit of one cattle monthly by specialized households $(\mathrm{H})$ are calf cost (X2), concentrated fodder (X4), water and fuel cost (X7), depreciation cost of fixed assets(X9), and selling cattle revenue(X11), the most important factor is concentrated fodder (X4), and the minimal factors are water and fuel cost (X7), depreciation cost of fixed assets(X9). The conclusion is useful to the government for the management of CFCR.

Scatterplot

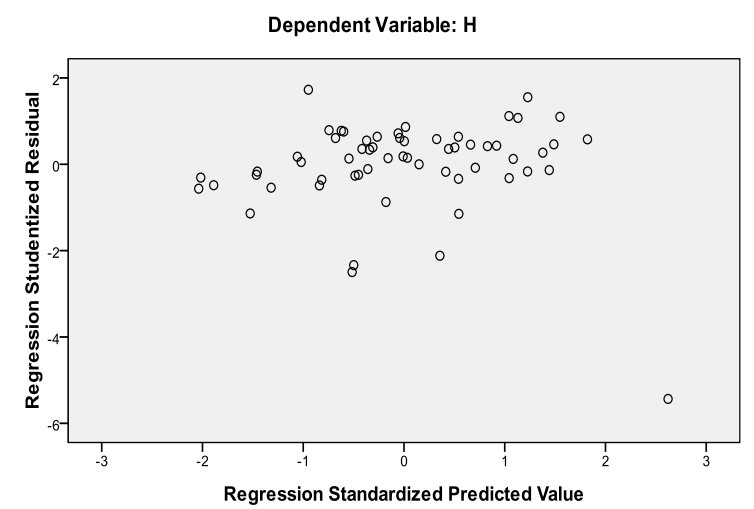

Fig.2 Scatter of ZPRED and SRESID

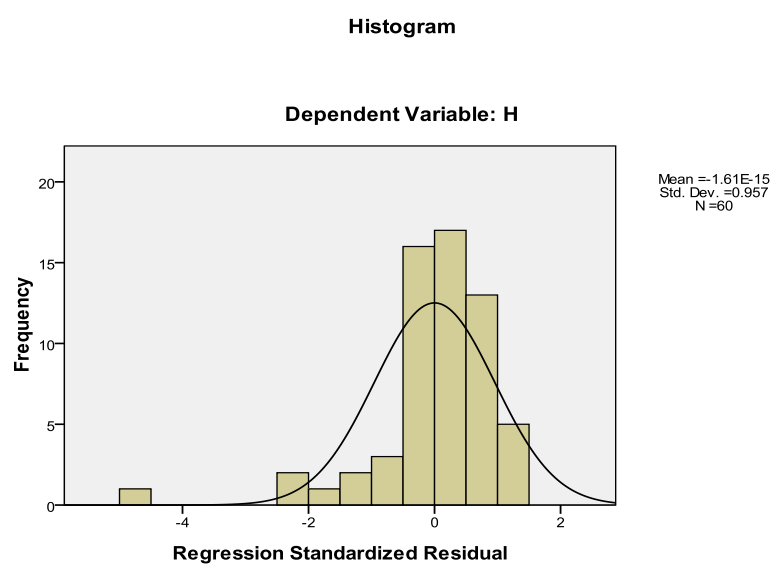

Fig.3 Bar of residual 


\subsection{The Minimum Scale}

The net income of specialized households by one cattle can be got from equation 7 when we learn that the profit of one cattle monthly is 159 on average. The calculating formula is,

$A=12 H=12 \times 159=1908$

At the same time, we also get the other data from the survey, $X=8683, L=2$, then, according to the equation 1 and equation 2, the minimum scale for cattle feeding would be 7 heads that can be got from the following formula,

$$
Y \geq \frac{\mu \cdot L \cdot X}{A}=\frac{0.7 \times 2 \times 8683}{1908}=6.371 \approx 7
$$

\subsection{The Net Loss of the Specialied Households}

The scale of feeding cattle by the local people is 3.2 heads on the average based the survey, so we can get the net loss of the specialized households from the equation 10 .

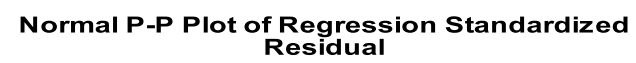
Residual

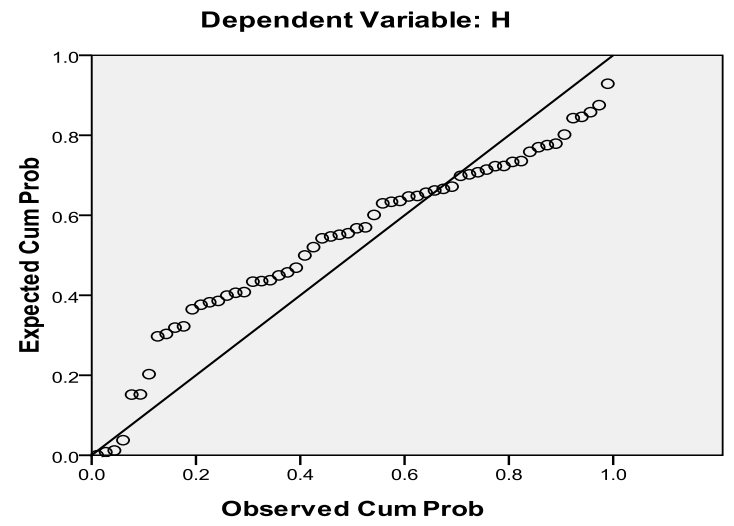

Fig.4 Normal P-P plot of residual

Here, we have the following data:

$Y_{1}=3.2, Y=6.371, A=1908$,

Then, we get the net loss through the following formula,

$Z=A\left(Y_{1}-Y\right)=1908 \times(3.2-6.371)=-6050$

That means the net loss of the specialized households in Yanshi County is 6050 RMB.

\section{Conclusion}

We can get the conclusion that the economic effectiveness of specialized households of CFCR in Yanshi County is bad, and the net loss compared with part-time job is about $6050 \mathrm{RMB}$. This is the reason why the local young people would go out for a work rather than feeding cattle at home. It is not good for the project of CFCR. The government should take some management methods to improve the project.

\section{Acknowledgments}

The paper has been sponsored by Key Technologies R\&D Program of China (Grant No. 2008BADC4B02).

We would like to thank Mr. Cheng-xue Feng from animal husbandry bureau of Henan province for preparing figures and other materials for presentation valuable comments. 


\section{References}

[1] Ting-shuang Guo, "integrated technology for CFCR", published by Chinese agricultural University press, Beijing, 1997

[2] Chinese husbandry yearbook, dited by the ministry of agriculture of China, Beijing, 2008

[3] Yu-feng Sun, "study on management of project of cattle feeding based on crop residues", published by Xi'an map press, Xi'an, China,2010

[4] Xiao-yan Cai, Shu-yan Guan and Zhi-jiang Lai, "our agricultural producers planting actuality and developing direction and prospect", the animal husbandry and veterinary communication of Shanghai, 2007, (4), pp.59-60

[5] national bureau of Chinese statistical yearbook, Beijing, Chinese statistical publishing house, 2008

[6] Gao-ming Jiang, "how to correctly understand sand storm and its management problems", http://www.grassland.gov.cn/GrasslandWeb/ sandstorm, ArticleID = rates

[7] Butterworth, M.H. and Mosi, A.K. (1985) Practical evaluation of crop residues and agroindustrial by-products for ruminants in developing countries with emphasis on East Africa. In: Preston, T.R., Kossila, VL., Goodwin, J. and Reed, R.J.S. (eds), Better Utilization of Crop Residues and By-Products in Animal Feeding. Food and Agriculture Organization of the United Nations, Rome, Italy, pp. 15-20..

[8] Adam Smith, "study on the causes of the wealth of nationl naature", published by Shanghai commercial press, Shanghai, 1996,5-12

[9] Richard Kurt, translated by Yan-kong, "agricultural marketing", published by Tsinghua University press, Beijing, 2006

[10]Ben-ting Li, Feng-xiang Zhang, "beef cattle breeding technology", published by Shandong science and technology press, Jinan, 1997

[11]Bing-long Li, Juan Qiao, Ke-san Wang, "the Comparative Study of sino0china agricultural policies under WTO rules" , published by China Agriculture Press, Beijing,2006

[12] National Development and Reform Commission, Ministry of Construction, "economic evaluation methods and parameters of construction project" (third edition), published by Chinese Plan Press, Beijing, 2006 